\title{
Consumer credit rules relaxed
}

\section{by James Dawson, Head of Advice Publications in the Practice Support team at the BDA}



ou can now allow patients to pay for their treatment in more instalments without needing authorisation from the Financial Conduct Authority (FCA). Not having to pay in one go can help many patients access the high quality care that they want. Generally, however, if you allow patients to pay for treatment by instalments or introduce them to a third party who will provide loans or other credit facilities you will need official consumer credit authorisation from the FCA. This can be a bureaucratic and expensive procedure, so the ability to let patients pay by instalments without needed FCA authorisation - as long as you comply with the FCA's precise conditions - can be helpful to you and your customers.

Enabling patients to get specialised care by deferring the cost over a number of payments can be done without FCA authorisation if the credit arrangement meets all of the FCA's criteria. Payment must be made in 12 or fewer instalments; the debt must be settled within 12 months; the arrangement must be for the purchase of specific goods or services - perhaps veneers or implants - that are provided directly by the practice; and the payments must be for an overall fixed amount with no charges, interest or administration fees. These - rules have been


allowing up to 12 instalments - previously the rules required four or fewer instalments. This affects any arrangements made since 18 March 2015.

To benefit from the exemption you must stick strictly to the FCA's requirements. Anything outside of this and authorisation is required, for instance if you let even a single patient pay in 13 or more instalments or let them pay over a period longer than one year. Also numerous other consumer credit activities require authorisation, though dental practices are most likely to need FCA approval if they: lend money; collect debts; introduce patients to a loan company to help them to finance their treatment; arrange credit through a third party; or administer credit agreements for a third party, even if this does not involve collecting debts. Authorisation is required even if you do not charge for providing the credit. Beware, it is a criminal offence to carry out activities requiring authorisation without permission and can lead to two years' imprisonment and a financial penalty.

\section{Applying for authorisation}

If the services you offer to patients mean that you are likely to need consumer credit authorisation then you need to apply to the FCA, go to www.fca.org.uk to use their on-line Connect system. Depending on your precise consumer credit activities you will need either full permission or limited permission; see the FCA website's Credit Ready Decision Tool to decide which type of authorisation you need.

Whether you need full or limited permission depends on your consumer credit activities and the financial risk of your business; as a lower-risk business, dentists will likely meet the requirements for limited permission.

You will need to submit detailed information about your practice, how it is managed and its finances. The FCA website has checklists of the information you will need to gather and guidance on the how to complete their application form. In assessing the fitness of an applicant to offer credit, the FCA will consider: your knowledge and experience of financial issues; your proposed practices and procedures for offering credit; any criminal convictions, breaches of consumer legislation, such as trading standards or advertising standards rules; and your personal solvency or insolvency. Past criminal convictions, insolvency or breaches of trading standards or advertising standards would be evidence of unfitness. Checks would also be undertaken with the General Dental Council.

Fees are payable when you apply for consumer credit authorisation and, thereafter, on an annual basis. Fees vary widely depending on the type of permission you have, the consumer credit activities that you do and the size of your business. Precise details on fees are available from the FCA website.

\section{Old licences}

The FCA took over the administration of consumer credit authorisation from the Office of Fair Trading (OFT) in April 2014. Previous OFT consumer credit licence holders had to reapply for authorisation, the old OFT licence longer being valid after 31 March 2014. If you previously held an OFT consumer credit licence you should have registered with the FCA for interim permission by the 31 March 2014. Those with interim permission will be directed to reapply for a full consumer credit authorisation in due course, probably sometime before 1 April 2016.

\section{Fee Collection}

BDA Advice Fee Collection - which can be found on the website at www.bda.org/advice provides further information.

James Dawson is responsible for the BDA's guidance documents for members in general practice on legal matters including associate contracts and staff employment

bdjteam201562 